\title{
COMPARATIVE STUDY ON THE BENEFICIAL EFFECTS OF TELMISARTAN AND OTHER ANTIHYPERTENSIVE AGENTS IN STROKE PATIENTS
}

\author{
ANJU JOSE ${ }^{1}$, DEEPTHI WILSON ${ }^{1}$, MINTU GEORGE ${ }^{1}$, RESHMA K. THOMAS ${ }^{1}$, A. JUSTIN ${ }^{1}$ \\ Department of Pharmacy Practice, PSG College of Pharmacy, Peelamedu, Coimbatore 64100 Tamil Nadu, India \\ Email: reshmakthomas@gmail.com
}

Received: 19 Oct 2016 Revised and Accepted: 07 Dec 2016

\section{ABSTRACT}

Objective: To compare the beneficial effects of telmisartan with other anti-hypertensive agents during stroke with respect to improvement from neurological dysfunction.

Methods: A prospective observational study was performed on 98 eligible study participants. The blood pressure, National Institute of Health Stroke Scale (NIHSS) score and power of limbs were noted. The data were analysed using one-way Analysis Of Variance (ANOVA) followed by Dunnett's Multiple Comparison Test.

Results: Among 150 randomised patients, 110 met the inclusion criteria, and 98 came for follow-up whose data was recorded. Telmisartan showed significant improvement in total NIHSS score compared to amlodipine ( $\mathrm{P} \leq 0.01)$ and mannitol $(\mathrm{P} \leq 0.01)$. The mean reduction in SBP and DBP was significant with respect to telmisartan compared to amlodipine ( $\mathrm{E} 0.01)$. Telmisartan showed significant im provement of power in right upper limb (UL) compared to amlodipine $(\mathrm{P} \leq 0.05)$ and mannitol $(\mathrm{P} \leq 0.01)$. Im provement of power in right lower limb (LL) showed significance with respect to telmisartan compared to mannitol ( $\mathbb{E}$ 0.05). Significant improvement of power in left LL was observed in tel misartan compared to mannitol $(\mathrm{P} \leq 0.01)$.

Conclusion: Blood pressure reduction is an inevitable component of stroke treatment. Anti-hypertensive treatment seems to be highly efficacious in protecting patients against stroke and stroke recurrence, especially on long term basis. Thus, telmisartan provides a viable insight into the stroke prevention strategy and may be prudent to consider as a reasonable add-on therapy.

Keywords: NIHSS, Anti-hypertensive agents, Telmisartan, Stroke

(C) 2017 The Authors. Published by Innovare Academic Sciences Pvt Ltd. This is an open access article under the CC BY license (http://creativecommons.org/licenses/by/4. 0/) DOI: http://dx.doi.org/10.22159/ijpps.2017v9i2.15755

\section{INTRODUCTION}

Telmisartan has a dual role of controlling blood pressure as well as exhibiting neuroprotection in brain attack conditions which may benefit stroke patients. Stroke is a neurodegenerative disease which is characterized by loss of brain function due to an obstruction of major cerebral arteries. The most common risk factor for stroke is hypertension. According to the guidelines by the British Hypertension Society and National Institute for Health and Clinical Excellence (NICE), the risk of stroke is reduced by $16 \%$ in patients on Angiotensin Receptor Blockers (ARB). The objective of the study was to evaluate the beneficial effects of telmisartan in the treatment of stroke. Previous studies indicate that Angiotensin Converting Enzyme Inhibitors (ACE-I) and ARB's are more effective in recurrent stroke prevention than other anti-hypertensive agents [1]. They exert multiple anti-atherogenic actions and reduce clinical events in high-risk patients. Among the ARB's used in the treatment of stroke, telmisartan has been found to directly ameliorate interleukin 1-beta induced a neuronal inflammatory response, by inhibition of oxidative stress and the c-Jun n-terminal kinases (JNKs) pathway. It attenuates the excitatory amino acid by controlling cytokines and reactive oxygen species released during ischemia. Peroxisome Proliferator-Activated Receptor-Gamma (PPAR- $\delta$ ) agonist property along with angiotensin receptor type-1 blockade may favour the neuroprotective effect during neurodegenerative conditions like cerebral ischemia [2]. Hence, the study determined the clinical significance of preferring telmisartan over other antihypertensive agents in stroke patients.

\section{MATERIALS AND METHODS}

\section{Study design}

The prospective observational study compared the beneficial effects of telmisartan with other anti-hypertensive agents during stroke with respect to improvement from neurological dysfunction. The study was approved by the human Institutional ethics committee (Ref: 15/018) and subsequently, it was carried out in collaboration with the department of neurology, PSG hospitals, Coimbatore between January 2015 and June 2015. Patient consent was obtained from all the study participants after explaining all aspects of the study.

\section{Subjects}

A group of 150 patients were randomised, 110 met the inclusion criteria, and 98 came for follow-up whose data were recorded. Of these, 30 were randomised into a control group, 32 in amlodipine group and 36 in telmisartan group. Out of these 98 patients, $70.408 \%$ $(n=69)$ comprised of males and $29.59 \%(n=29)$ were females. The patients in the age group of 35-85 y participated, in which patients of 51-60 y (39.78\%) were predominant. Most of the patients had a medical history of diabetes $(8.1 \%)$ and hypertension $(21.4 \%)$. Patients with heart failure, cancer, pregnant women and those who were not part of an anti-hypertensive therapy were excluded as they will interfere with the sensitivity of the outcome.

\section{Study tools}

\section{NIHSS}

NIHSS is composed of 11 items, each of which scores between 0 and 4. For each item; a score of 0 typically indicates a normal function in that specific ability, while a higher score is an indication of some level of impairment. The maximum possible score is 42 , with the minimum score being 0 .

\section{Power}

The power of limbs was determined by the physician, and given a score out of 5 for each limb, to assess the neurological function. 


\section{Blood pressure}

The Blood Pressure (BP) was recorded at the time of admission and during the review to evaluate which agent exhibits better control of hypertension.

\section{Statistical analysis}

Statistical analysis was carried out with one-way ANOVA followed by Dunnett's Multiple Comparison Test. Data were expressed as mean \pm standard deviation (SD). Here, mean indicates the difference between NIHSS score before and after treatment. Superscript $a, b$ and c denotes significance of telmisartan at $\mathrm{P}<0.05, \mathrm{P}<0.01$ and $\mathrm{P}<0.001$ versus amlodipine; Superscript $\mathrm{x}, \mathrm{y}$ and $\mathrm{z}$ denotes significance at
$\mathrm{P}<0.05, \mathrm{P}<0.01$ and $\mathrm{P}<0.001$ versus mannitol.

\section{RESULTS}

\section{Baseline characteristics of the study groups}

The demographic and clinical characteristics of the 98 study subjects are provided in table 1 . Among the 69 males and 29 females who were enrolled in the study, $54 \%$ came with complaints of right side weakness and $46 \%$ with left side weakness. The mean BP of patients during the time of admission was found to be $148 / 91 \mathrm{mmHg}$. The prevalence of hypertension in the participants was $57 \%$. Subsequently, 30 patients were treated with mannitol, 32 with amlodipine and 36 patients were on telmisartan.

Table 1: Baseline characteristics

\begin{tabular}{|c|c|c|c|}
\hline Variable & Mannitol & Amlodipine & Telmisartan \\
\hline Age & $56.33 \pm 13.89$ & $60.765 \pm 10.548$ & $57.31 \pm 09.844$ \\
\hline \multicolumn{4}{|l|}{ SBP (mmHg) } \\
\hline Admission & $150.1 \pm 26.146$ & $143.1 \pm 24.55$ & $150.6 \pm 23.17$ \\
\hline Discharge & $125.8 \pm 13.266$ & $129.69 \pm 15.34$ & $125.0 \pm 15.9$ \\
\hline \multicolumn{4}{|l|}{$\mathrm{DBP}(\mathrm{mmHg})$} \\
\hline Admission & $93.07 \pm 14.32$ & $85.0 \pm 14.14$ & $94.03 \pm 19.67$ \\
\hline Discharge & $80.03 \pm 8.34$ & $81.56 \pm 10.50$ & $84.40 \pm 9.39$ \\
\hline Smoking/nonsmoking (n \%) & $36.66 / 63.33$ & $31.25 / 68.75$ & $50 / 50$ \\
\hline Previous history of stroke/No history (n \%) & $13.33 / 86.67$ & $15.625 / 84.37$ & $8.33 / 91.67$ \\
\hline Previous history of Hypertension/No history (n \%) & $56.66 / 43.33$ & $56.66 / 43.33$ & $61.11 / 38.88$ \\
\hline
\end{tabular}

SBP-Systolic Blood Pressure, DBP-Diastolic Blood Pressure, $n=110$, values are expressed as mean \pm SD

Comparison of the mean difference in NIHSS during admission and review among three treatment groups

The telmisartan group showed a better improvement in the neurological function as depicted in fig 1.

Statistical analysis was performed using One-way ANOVA followed by Dunnett's multiple comparison tests. Data were expressed as mean \pm SD. Here, mean indicates the difference between NIHSS score before and after treatment. Superscript a, b and c denotes significance of telmisartan at $\mathrm{P}<0.05, \mathrm{P}<0.01$ and $\mathrm{P}<0.001$ versus amlodipine; superscript $\mathrm{x}, \mathrm{y}$ and $\mathrm{z}$ denotes the significance of telmisartan at $\mathrm{P}<0.05, \mathrm{P}<0.01$ and $\mathrm{P}<0.001$ versus mannitol.

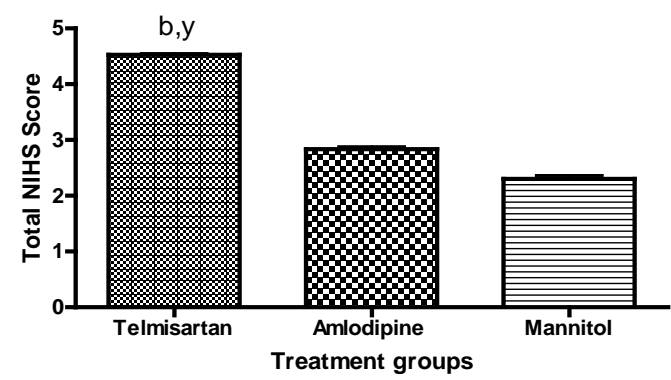

Fig. 1: Statistical significant difference of total NIHSS Score among treatment groups, Superscript "b" denotes significance of telmisartan at $P<0.01$ versus amlodipine; superscript " $y$ " denotes significance of telmisartan at $P<0.01$ versus mannitol

Telmisartan significantly improved the NIHSS Score with respect to Level of Consciousness (LOC) compared to mannitol $(\mathrm{P}<0.05)$ and amlodipine $(\mathrm{P}<0.05)$. The NIHSS score of LOC commands, facial palsy, motor function of leg and limb ataxia showed significance in telmisartan with respect to amlodipine $(\mathrm{P}<0.01)$ and mannitol $(\mathrm{P}<0.01)$.

Telmisartan showed significant improvement in NIHSS score of best gaze and visual compared to mannitol $(\mathrm{P}<0.05)$. This is represented in table 2.

Categorization based on the difference in power of limbs during admission and follow-up among the treatment groups

Telmisartan showed significant improvement of power in right UL compared to amlodipine $(\mathrm{P}<0.05)$ and mannitol $(\mathrm{P}<0.01)$. However, improvement of power in right LL was observed with telmisartan compared to mannitol $(\mathrm{P}<0.05)$. Significant improvement of power in left LL was observed in telmisartan compared to mannitol $(\mathrm{P}<0.01)$. This is represented in fig. 2 .

\section{Mean blood pressure reduction among different treatment groups}

The telmisartan treated group had a high mean SBP difference of 25.6 compared to other groups. This is presented in the table- 3 . However, mannitol showed a better reduction in DBP with respect to other drugs.

\section{DISCUSSION}

Hypertension is an important modifiable risk factor for stroke. The prevalence of hypertension in the participants was $57 \%$ and the mean $\mathrm{BP}$ of patients during the time of admission was found to be 148/91 mmHg. According to the guidelines by the British Hypertension Society and National Institute for Health and Clinical Excellence (NICE), the risk of stroke is reduced by $16 \%$ in patients on angiotensin receptor blockers. They have proven to be effective via mechanisms that include not just inhibition of the peripheral and central actions of angiotensin-II mediated by AT1 receptors but also stimulation of unopposed angiotensin-II type 2 (AT2) receptors that are upregulated in areas of ischemia [1]

The study on cognition and prognosis in the elderly (SCOPE) study established risk reduction in all elderly patients treated with candesartan-based regimen compared with a control group [3]. The stroke results in patients with isolated systolic hypertension in the SCOPE study are in line with the findings in the Losartan Intervention for Endpoint reduction (LIFE) study. The results reported by the LIFE investigators revealed that there is a substantial reduction in stroke events $(40 \%)$ and CV mortality $(46 \%)$ in losartan-based anti-hypertensive regimen compared to atenololtreated patients [4]. 
Table 2: Difference in NIHSS among the three treatment groups

\begin{tabular}{llll}
\hline Parameters & mannitol & amlodipine & telmisartan \\
\hline LOC & $0.343 \pm 0.314$ & $0.388 \pm 1.666$ & $0.5666 \pm 0.412^{\mathrm{a}, \mathrm{x}}$ \\
LOC questions & $0.533 \pm 0.196$ & $0.625 \pm 0.446$ & $0.722 \pm 0.330$ \\
LOC commands & $0.266 \pm 0.168$ & $0.562 \pm 0.132$ & $0.805 \pm 0.082^{\mathrm{b}, \mathrm{y}}$ \\
Best gaze & $0.093 \pm 0.296$ & $0.2 \pm 0.260$ & $0.252 \pm 0.292^{\mathrm{x}}$ \\
Visual & $0.031 \pm 0.069$ & $0.1 \pm 0.207$ & $0.194 \pm 0.318^{\mathrm{x}}$ \\
Facial palsy & $0.366 \pm 0.304$ & $0.531 \pm 0.239$ & $0.75 \pm 0.317^{\mathrm{b}, \mathrm{y}}$ \\
Motor function(arm) & $1 \pm 0.266$ & $1.125 \pm 0.176$ & $1.111 \pm 0.252$ \\
Motor function (leg) & $0.866 \pm 0.11$ & $0.968 \pm 0.054$ & $1.138 \pm 0.306^{\mathrm{b}, \mathrm{y}}$ \\
Limb ataxia & $0.5 \pm 0.119$ & $0.5 \pm 0.255$ & $0.666 \pm 0.216^{\mathrm{b}, \mathrm{y}}$ \\
Sensory & $0.218 \pm 0.209$ & $0.249 \pm 0.292$ & $0.3 \pm 0.316$ \\
Language & $0.312 \pm 0.263$ & $0.366 \pm 0.3449$ & $0.416 \pm 0.273$ \\
Articulation & $0.1 \pm 0.243$ & $0.343 \pm 0.545$ & $0.222 \pm 0.202$ \\
Extinction and inattention & $0.133 \pm 0.278$ & $0.218 \pm 0.335$ & $0.133 \pm 0.278$ \\
Total NIHSS & $2.3003 \pm 0.336$ & $2.835 \pm 0.244$ & $4.5273 \pm 0.120^{\mathrm{b}, \mathrm{y}}$ \\
\hline
\end{tabular}

LOC-Level of Consciousness, Superscript a, b and c denotes significance of telmisartan at, $\mathrm{P}<0.05, \mathrm{P}<0.01$ and $\mathrm{P}<0.001$ versus amlodipine; superscript $x, y$ and $z$ denotes significance at $\mathrm{P}<0.05, \mathrm{P}<0.01$ and $\mathrm{P}<0.001$ versus mannitol.

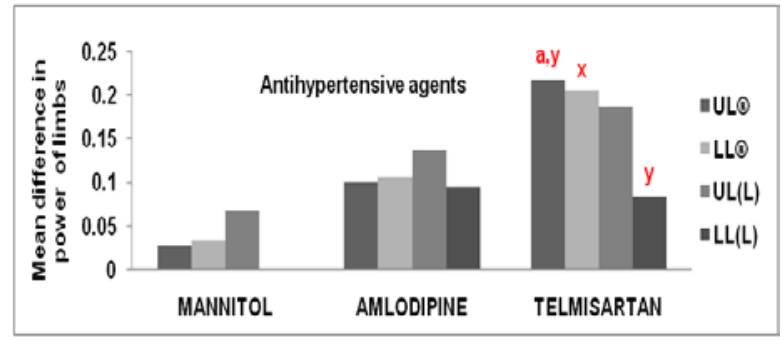

Fig. 2: Mean difference in power of limbs between admission and follow-up, UL@-Right Upper Limb, LL@-Right Lower Limb, UL (L)-Left Upper Limb, LL (L)-Left Lower Limb. Superscript "a" denotes significance at $P<0.05$ versus amlodipine; Superscript " $x, y$ " denotes significance at $P<0.05$ and $P<0.01$ versus mannitol

Table 3: Comparison of mean blood pressure reduction among three treatment groups

\begin{tabular}{lll}
\hline Drugs & $\begin{array}{l}\text { Mean Reduction in SBP } \\
\text { (mmHg) }\end{array}$ & $\begin{array}{l}\text { Mean Reduction in DBP } \\
\text { (mmHg) }\end{array}$ \\
\hline mannitol & $24.3 \pm 12.88$ & $13.04 \pm 5.973$ \\
amlodipine & $13.5 \pm 9.21$ & $3.44 \pm 3.494$ \\
telmisartan & $25.6 \pm 7.27^{\mathrm{b}}$ & $9.63 \pm 10.28^{\mathrm{b}}$ \\
\hline
\end{tabular}

SBP-Systolic Blood Pressure, DBP-Diastolic Blood Pressure, The mean reduction in SBP and DBP was significant with respect to telmisartan compared to amlodipine $(\mathrm{P}<0.01)$

The study demonstrated a reduction in blood pressure in all the three groups. The blood pressure reduction was slightly better $(25.6 / 9.63 \mathrm{mmHg})$ with the telmisartan-based regimen compared with amlodipine. It is possible that these relatively small differences in blood pressure could account for part of the observed clinical benefits on stroke. In epidemiological studies, it has been shown that there is a decrease in risk of stroke by approximately one-third for persons aged $60-79 \mathrm{y}$ for each $10 \mathrm{mmHg}$ reduction in systolic blood pressure [5].

Preclinical studies demonstrate that telmisartan has a dual role of controlling blood pressure as well as exhibiting neuroprotection in brain attack conditions which benefits stroke patients.

The ONTARGET (2009) trial has compared the ARB, telmisartan against the ACE-I, ramipril in patients at high risk for cardiovascular events. Both treatments were equally effective in reducing cardiovascular end points, although protection against stroke was slightly better $(9 \%)$ in telmisartan-treated patients [6]. Hence, the study evaluated the clinical significance of telmisartan, by comparing the neurological improvement between telmisartan and other antihypertensive agents, using the NIHSS score during admission and at the time of review. Telmisartan based treatment was associated with a statistically significant difference in the NIHSS score $(\mathrm{P}<0.01)$ between admission and follow-up, which is a noteworthy observation that points out the neuroprotective effects of telmisartan in stroke patients.

Stroke patients demonstrate a significant decrease in muscle power performance after stroke. Motor function is affected due to focal brain lesions which develop due to decrease in oxygen levels in the blood. When the limb function is affected, it impairs the daily activities of a person. Telmisartan controls cytokines and reactive oxygen species released during ischemia and accordingly helps in the improvement of motor function. Somatostatin sensory input and spasticity is improved by rehabilitation, but the complete recovery occurs only when both cognitive and motor functions are restored in the patient. In the study, a significant improvement in power of right limbs and left lower limb was observed with telmisartan. Therefore, optimising the power level would contribute to better functional outcome in stroke patients.

\section{CONCLUSION}

Blood pressure reduction is an inevitable component of stroke treatment. Anti-hypertensive treatment seems to be highly efficacious in protecting patients against stroke and stroke recurrence, especially on a long-term basis. The study of telmisartan based treatment compared to other anti-hypertensive agents showed that in addition to blood pressure control, telmisartan exhibits better neuroprotection by the attenuation of inflammatory cytokines and excitatory amino acids, which is portrayed in the improvement of limb power and NIHSS score. Thus, telmisartan provides a viable insight into the stroke prevention strategy and may be prudent to consider as a reasonable add-on therapy.

\section{Limitations}

The study duration may have been too short to assess the complete effect of telmisartan treatment in stroke patients. Moreover, details of the infarct size were not available for all patients who were enrolled in the study and hence it was not used as a parameter for comparison. The study was not done within the group and further study needs to be done in a large population to fully understand the benefits and role of telmisartan in the treatment regimen of stroke.

\section{CONFLICT OF INTERESTS}

\section{Declared none}

\section{REFERENCES}

1. Thone-Reineke, Steckelings Um, Unger T. Angiotensin receptor blockers and cerebral protection in stroke. J Hypertens 2006;24 Suppl 1:115-21. 
2. Kakuta H, Suboh K, Sasamata M, Yamaqishi S. Telmisartan has the strongest binding affinity to angiotensin-II type 1 receptor: comparison with another angiotensin-II type 2 receptor blockers. Int J Clin Pharmacol Res 2005;25:41-6.

3. Vasilios Papademetriou, C Farsang, D Elmfeldt. Stroke prevention with the angiotensin-II type 1 receptor blocker, Candesartan in elderly patients with isolated systolic hypertension: a study on cognition and prognosis in the elderly (SCOPE). J Am Coll Cardiol 2004;44:1175-80.

4. Paulette A Lyle, Kjeldsen SE, Kizer JR. The effect of losartan compared to atenolol on stroke in patients with isolated systolic hypertension and left ventricular hypertrophy: the LIFE study. J CLIN Hypertens 2005;7:152-8.

5. Venkatesh Aiyagari, Philip B Gorelick. Management of blood pressure for acute and recurrent stroke. STROKE AHA 2009;40:2251-6.

6. Mann JF, Anderson C, Gao P. Dual inhibition of renninangiotensin system in high-risk diabetes and risk for stroke and other outcomes: the result of ONTARGET trial. J Hypertens 2013;31:414-21.

7. D Giri Rajasekhar, D Guru Prasanna, P Chandrakanth Prescribing pattern of antihypertensive drugs based on compelling indications with hypertension. IAS 2016;8:72-5.

8. Devender Kodati, Harikiran Lingabathula, Narsimha Reddy Yellu. Effect of Olmesartan and Labetolol on oxidative stress and antioxidant status in south Indian hypertensive patients. Asian J Pharm Clin Res 2016;9:307-10.

9. Bjorn Dahlof. Prevention of stroke: new evidence. Eur Heart J 2009;11 Suppl 1:33-8.

10. Fuentes B, Fernandez-Dominquez J, Ortega-Casarrubios MA, San Jose B, Martinez-Sanchez P, Diez-Tejedor E. Treatment with angiotensin receptor blockers before stroke could exert a favorable effect in acute cerebral infarct. J Hypertens 2010;28:575-81.

11. Gui Jv Chen, Mao Sheng Yang. The effects of CCB's in the prevention of stroke in adults with hypertension: a metaanalysis of data from 273,543 participants in 31 randomised controlled trials. PLOS One 2013;8:1-9.

12. Jose Castillo, Rogelio Leira, Maria M Garcia, Joaquin Serena Miguel Blanco, Antoni Davalos. Blood pressure decrease during the acute phase of ischemic stroke is associated with brain injury and poor stroke outcome. Stroke 2004;35:520-6.
13. Meng Lee, Jeffrey L Saver, Keun-Sik Hong, Quing Hao, Jessica Chow, Bruce Ovbiagele. Renin-angiotensin system modulators modestly reduce vascular risks in persons with prior stroke. Stroke 2012;43:113-9.

14. Liu Lisheng, Wang, Ji-Guang, Gong L, Liu G, Staesscn JA. Comparison of the active treatment and placebo in older Chinese patients with isolated systolic hypertension in China (Syst-China) collaborative group. J Hypertens 1998;16:1823-9.

15. Volpe M, Ruilope LM, Mclnnes GT, Waeder B, Weber MA Angiotensin-II receptor blockers: benefits beyond blood pressure reduction? J Hum Hyperten 2005;19:331-9.

16. Paolo Verdecchia, Gentile G, Angeli F, Reboldi G. Beyond blood pressure: Evidence for cardiovascular, cerebrovascular and renal protective effects of Rennin-angiotensin system blockers. Ther Adv Cardiovasc Dis 2012;6:81-91.

17. Parveen Rashid, Jo Leonardi-Bee, Phillp Bath. Blood pressure reduction and secondary prevention of stroke and other vascular events. Stroke 2003;34:2741-8.

18. Bath PM, Martin RH, Paleschy. Effect of telmisartan on functional outcome, recurrence and blood pressure in patients with acute mild ischemic stroke. A PRoFESS subgroup analysis. Stroke 2009;40:3541-6.

19. Roberta Ravenni, Joe F Jabere, Edoardo Casiglia, Alberto Mazza Primary stroke prevention and hypertension treatment: which is first line therapy? Neurol Int 2011;3:12.

20. SG Chrysant. Angiotensin receptor blocker provides better stroke protection than angiotensin converting enzyme inhibitors-a hypothesis with clinical and experimental support. Hippokratia 2005;9:99-105.

21. Unger. Blood pressure is lowering and rennin-angiotensin system blockade. J Hypertens 2003;21 Suppl 1:3-7.

22. Weber. The telmisartan programme of research to show telmisartan end-organ protection programme. J Hypertens 2003;6 Suppl 1:37-46.

\section{How to cite this article}

- $\quad$ Anju Jose, Deepthi Wilson, Mintu George, Reshma K Thomas, A Justin. Comparative study on the beneficial effects of telmisartan and other antihypertensive agents in stroke patients. Int J Pharm Pharm Sci 2017;9(2):99-102. 